\title{
DISSOLVED OXYGEN AND NUTRIENTS IN COASTAL WATERS IMPACTED BY THE STRYMON RIVER PLUME, NORTH AEGEAN SEA, GREECE
}

\section{A. PAVLIDOU* \\ D. GEORGOPOULOS}

Received: 16/05/01

Accepted: 25/10/01
National Center for Marine Research

Agios Kosmas 16604, Athens, Greece

* to whom all correspondence should be addressed tel.: +30-10-9653521; fax: +30-10-9653522

e-mail: aleka@fl.ncmr.gr

\begin{abstract}
Three hydrographic cruises were conducted during 1997-1999 in north Aegean Sea, in order to study the dissolved oxygen (DO) and nutrient distributions in Strymonikos Gulf impacted by the riverine waters of the Strymon River.

The approaches used in this paper include a preliminary estimation of the nutrient load of Strymon River and the influence of the riverine waters upon the DO and nutrient distribution in Strymonikos Gulf. Nutrient levels recorded in Strymon River were similar with other international Rivers.

The influence of Strymonas River on the DO and nutrient distributions was clearly detected during December 1997 and May 1998. On the contrary, during March 1999 the influence of Strymon River was not so clearly detected. High nutrient concentrations were recorded close to the mouth of the river. As mixing with offshore waters progressed, nutrient levels declined dramatically.

Plots of atomic DIN:P (ratio of the total dissolved inorganic nitrogen to dissolved inorganic phosphorus), Si:P (ratio of dissolved silica to dissolved inorganic phosphorus) and Si:DIN ratios in Strymonikos Gulf, during the three sampling periods studied, indicated stoichiometric P-limitation in about 34\%. Furthermore, the data indicated significant probable N-limitation (31.4\%), while Si-limitation was not probable $(2.9 \%)$. In particular, $31 \%$ of the data showed a defined P-limitation in December, whereas $30 \%$ of the data showed N-limitation. It is noteworthy that Si-limitation was not recorded. In May, the atomic DIN:P ratio indicated P-limitation in about $21 \%$ and $\mathrm{N}$-limitation in about $46 \%$. Si-limitation was not recorded. Finally, in March, the $51 \%$ of the data showed P-limitation, whereas only the $16 \%$ showed N-limitation and $8 \%$ showed Si-limitation.
\end{abstract}

KEYWORDS: Nurients, Strymonikos Gulf, Strymon River, coastal, Dissolved Oxygen.

\section{INTRODUCTION}

Nutrient concentration monitoring is of great interest in environmental research, since the increasing input of nutrients may result in a change of the trophic status of an ecosystem. Eutrophication and/or oxygen depletion has been reported from a variety of greek coastal marine ecosystems (Friligos et al., 1997; Pavlidou and 
Krasakopoulou, 2000; Pavlidou et al., 2001a). The influence of the riverine discharges the coastal waters has become one of the major concerns of the scientific community, since the frequency and extent of eutrophication may be increased in coastal waters affected by riverine inflows (Justic et al., 1995).

It has been postulated that the changes in agricultural practices in the last century (use of fertilisers, mechanisation and drainage) have significantly contributed to the increase of nutrient concentrations in the riverine waters, determining the nutrient distribution in the coastal ecosystems affected by riverine waters. This influence is apparently restricted very close to the river mouths.

Small rivers, which have an important local bearing as regards coastal fertilisation affecting coastal marine ecosystems, continue to be a matter of concern throughout the world.

Strymon River is considered to be the greatest river in the Western part of Bulgaria. Its catchment area in Bulgaria is $10800 \mathrm{~km}^{2}$, whereas in Eastern Macedonia Strymon basin covers an area of $2700 \mathrm{~km}^{2}$.

Strymon River originates in the Vitosha Mountain in Bulgaria (Tryfon et al., 1996; Veleva, 2000), runs first westward, then southward, enters the Greek territory and flows into the north Aegean Sea in the Strymonikos Gulf. It has a total length of about $360 \mathrm{~km}$, the $122 \mathrm{~km}$ within Greece. The total annual water discharge is around 2 billion $\mathrm{m}^{3}$, which is about $50 \%$ lower than the corresponding volume measured during 1987-90.

Recent measurements (Lazaridou et al., 2001) have recorded that $\mathrm{pH}$ values varied between 7 and 8.23 , whereas the mean conductivity recorded was $360 \mu \mathrm{Mhos} \mathrm{cm}^{-1}$. It is noteworthy that high values of $\mathrm{Pb}$ and $\mathrm{Cd}$ have been recorded, probably related to a specific polluting source (Lazaridou et al., 2001).

In the river valley of the Strymon River a lot of artificial lakes - hydropower reservoirs have been made (Pyrovetsi and Papastergiadou, 1992; Veleva, 2000), as well as dams, which interrupt the water supply of the riverbed. One of the most known artificial lakes in Greece is the Kerkini Lake, which lies $47 \mathrm{~km}$ from the Greek Bulgarian border. This is resulting to the dramatic decrease of the flow rate of Strymon River, especially during summer. Since the retention of the water behind the dams takes place occasionally, the water discharges of River Strymon fluctuate during a year. Generally, the minimum flow rate values are observed in dry season, whereas, in periods of rainfall the flow rate of the river is increased (Scoulikidis, 1997).

Regarding nutrients, it has been reported (Tryfon et al., 1996) that nutrient values measured in Strymon River during 1991-1992 did not indicate strong anthropogenic effects.

Strymonikos Gulf receives pollutants from point sources such as Stavros village or other villages and small towns and/or streams-small rivers (such as Richios River) discharging in the Strymonikos Gulf, in the area between Strymon River and Stavros (Figure 2). The contribution of the villages, small cities and the streams is not significant and no industries have been recorded in the study area.

The region of the Strymonikos Gulf represents a coastal ecossystem, which is impacted mainly by riverine waters. The trophic status of the gulf is a matter of concern, since many anthropogenic activities (e.g. fishing, tourism) are performed in or/and near the gulf with serious socioeconomic impact.

In the present work, the DO and nutrient distribution in Strymonikos Gulf affected by Strymon River is presented, in order to evaluate the importance of the influence of riverine waters on a coastal marine ecosystem. This study has been performed within the framework of INTERREG program monitoring for the study of inter-regional pollution in north Aegean Sea.

\section{METHODS}

Seawater samples were collected on three hydrographic cruises (December 1997, May 1998 and March 1999), over a grid of 20 sampling stations in Strymonikos Gulf (Figures 1 and 2) and one sampling station in Strymon River, near the mouth of the River. The water samples were collected at the standard depths $(2,10,20,50,75$, 100 , etc and $2-3 \mathrm{~m}$ above the sea bottom), using NISKIN bottles.

DO measurements were performed on board, immediately after sampling (Riley, 1975), using the Winkler method (Carritt and Carpenter, 1960).

Phosphates and ammonium were measured with a Perkin Elmer UV/VIS (Lambda 2S) spec- 


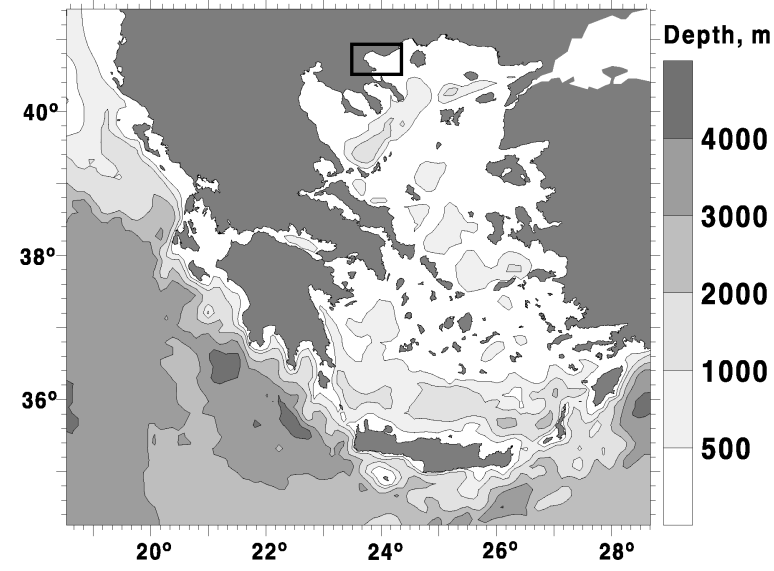

Figure 1. Location of the study area in Greece

trophotometer, using standard methods (Murphy and Riley, 1962, for phoshates and Koroleff, 1970, for ammonium), whereas silicates, nitrites and nitrates were measured with a BRAN+LUEBBE autoanalyser following standard methods (Mullin and Riley, 1955, for silicates, Stickland and Parsons, 1968, for nitrites-nitrates).

\section{RESULTS AND DISCUSSION River Nutrient Data}

Nutrient concentrations have been measured in Strymon River during two sampling periods (May 1998 and March 1999), in order to estimate the ecological status of the river. Samples were taken at a sampling station located at the rivershore, near the river mouth $(\sim 500-600 \mathrm{~m}$ from the mouth of the river). Since the sampling station at the

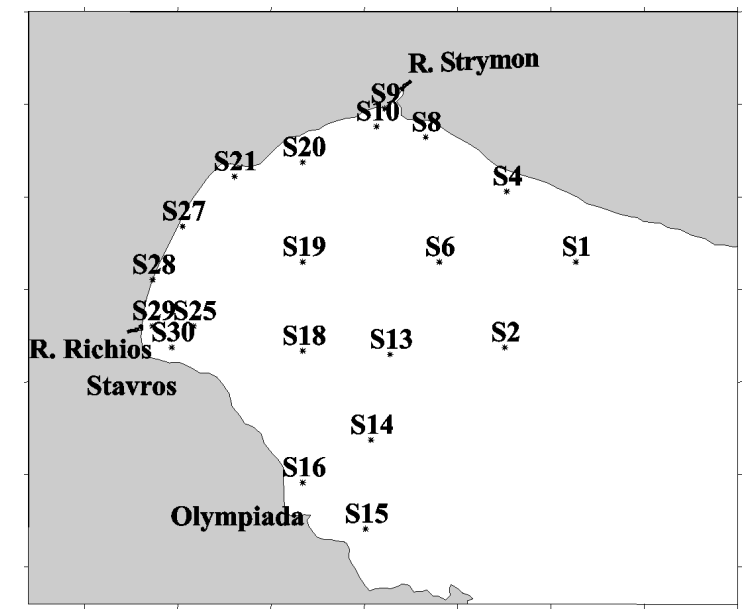

Figure 2. Location of sampling stations in the Strymonikos Gulf rivershore was very shallow and was also characterized by high turbidity, it was not possible to receive proper samples for the DO measurement. Although there were not measurements on the water discharges of Strymon River during the sampling periods, taking into account the frequency of the rainfall events for both sampling periods (May 1998 and March 1999), they were supposed to be wet periods. Therefore, the water discharge of the River was rather increased during the sampling periods. The necessity of controlling the water flow in order to cover the agricultural activity, especially during summer, as well as the decrease of the rainfall levels, have decreased dramatically the riverine water during summer. Consequently, there are no data available during the dry period.

Nutrient measurements performed in riverine waters during the sampling cruises carried out in May 1998 and March 1999, showed high values of nitrates and silicates, indicating that Strymon River is rather polluted by agricultural activities. According to Tryfon et al. (1996), the phytoplankton species composition and their periodicity in the Strymon River resemble those of typical, large and nutrient-rich rivers of Europe.

Nitrite and ammonium percentages were calculated to be between $4-5 \%$ of DIN in both of the sampling cruises. Nitrates are therefore the main source of inorganic river nitrogen to the Strymon River, as generally occurs in riverine waters (Meybeck, 1982). Nutrient concentrations measured in riverine waters during May 1998 were recorded as follows: phosphates: $0.42 \mu \mathrm{M}$, silicates: $76.8 \mu \mathrm{M}$, nitrites: $1.87 \mu \mathrm{M}$, nitrates: $111 \mu \mathrm{M}$ and ammonium: $4.88 \mu \mathrm{M}$. During March 1999 nutrient concentrations did not show significant differences and were measured as follows: phosphates: $0.50 \mu \mathrm{M}$, silicates: $69.0 \mu \mathrm{M}$, nitrites: 1.17 $\mu \mathrm{M}$, nitrates: $150 \mu \mathrm{M}$ and ammonium: $5.10 \mu \mathrm{M}$. Nutrient levels recorded in Strymon River were similar with other international Rivers (Justic et al., 1995; Jarvie et al., 1998; Zhang et al., 1999; Bode and Dortch, 1996; Kormas, 1999) showing that Strymon River is evaluated to be a rather eutrophic river (Ignadiades et al., 1992). Meybeck (1982) has provided a regional examination relating DIN:P ratios to primary productivity and eutrophication in rivers (Meybeck, 1982; Jarvie et al., 1998). It seems 
Table 1. Dissolved Oxygen $\left(\mathrm{ml} \mathrm{l}^{-1}\right)$ and Nutrient ranges $\left(\mu \mathrm{mol} \mathrm{l}^{-1}\right)$ in Strymonikos Gulf.

\begin{tabular}{|c|c|c|c|}
\hline & December 1997 & May 1998 & March 1999 \\
\hline Diss. Oxygen & $5.16-6.92$ & $4.36-6.88$ & $4.48-7.32$ \\
\hline$\%$ Saturation & $91-107$ & $78-132$ & $73-128$ \\
\hline $\mathrm{P}^{-\mathrm{PO}_{4}^{3--}}$ & $0.03-0.87$ & $0.03-1.59$ & $0.01-0.71$ \\
\hline $\mathrm{Si}^{-\mathrm{SiO}_{4}^{2-}}$ & $1.41-46.3$ & $2.38-43.1$ & $0.04-66.1$ \\
\hline $\mathrm{N}-\mathrm{NO}_{2}^{-}$ & $0.15-1.05$ & $0.00-2.29$ & $0.00-0.90$ \\
\hline $\mathrm{N}-\mathrm{NO}_{3}^{-}$ & $0.00-34.4$ & $0.00-44.0$ & $0.00-59.8$ \\
\hline $\mathbf{N}-\mathrm{NH}_{4}^{+}$ & $0.00-1.71$ & $0.09-1.15$ & $0.05-1.45$ \\
\hline
\end{tabular}

that four ratio classes are used in riverine waters, in order to evaluate whether the organisms show $\mathrm{N}$ - or P-limitation (Jarvie et al., 1998). These four classes are: mass DIN:P ratio $<8,8-15,16-23$ and $>24$. The more records for a site towards the first category, the greater the likelihood that organisms may show N-limitation (Jarvie et al., 1998).

In Strymon River the atomic DIN:P ratio, which is calculated as the ratio of total dissolved inorganic nitrogen to dissolved inorganic phosphorus, corresponds to 280 (mass ratio 177) during May 1998 and 313 during March 1999. The atomic DSi:DIN ratio, which is calculated as the ratio of dissolved reactive silicate to dissolved inorganic nitrogen was calculated to be 0.65 during May 1998 and 0.44 during March 1999, whereas the atomic DSi:P ratio was calculated to be approximately 183 during May 1998 and 138 during March 1999.

Since the DSi:DIN is calculated to be less than 1:1, during spring (May 1998 and March 1999), it is supposed that $\mathrm{Si}$ can be depleted well before DIN and dissolved inorganic phosphorus (Officer and Ryther, 1980). Thus the resulting Si deficiency may favor the predominance of non-siliceous phytoplankton, which is often associated with undesirable effects of eutrophication (Justic et al., 1995). Probably, this is not the case of Strymon River, since the silicate levels were not significantly depleted.

According to the calculated ratios it seems that the Strymon River is P-limited. (Justic et al., 1995; Jarvie et al., 1998). Since DIN:P mass ratio is much higher than 20, the Strymon River may be an agricultural river rather than an urban and/or industrial one (Jarvie et al., 1998).

\section{Coastal DO and Nutrient data}

Dissolved oxygen and nutrient (silicates, nitrates, nitrites, phosphates and ammonium) ranges in Strymonikos Gulf during the three sampling periods are shown in Table 1.

DO data sets showed that the waters near the mouth of the river (marine site) were well oxygenated. The highest DO values were observed during March 1999, whereas relatively low values were recorded during May 1998 (Figures 3-5), at the discharge area. Relatively low DO concentrations were also recorded in Stavros area (mainly during March 1999), near the mouth of Richios River (located near Stavros village, Figure 2), indicating that there are other small point sources that play role in the distribution of DO in the study area. DO surface distribution in May 1998 showed a decreasing trend of DO concentrations towards the mouth of Strymon River (Figure 4). These observations may lead to the assumption that oxygen depletion may occur during summer. Unfortunately, due to technical problems, no sampling cruises were performed during summer. During May 1998 and March 1999 an anticyclonic gyre can be identified in Strymonikos Gulf, which inflected the water mass entering the Gulf towards the south-eastern part of the Gulf. High DO values were found in the centre of the anticyclonic gyre. DO distrubution at $50 \mathrm{~m}$ depth is determined mainly by the circulation of the water masses as well as by the waters from the Aegean sea entering in the Gulf (Figure 6).

The DO vertical distributions along a transect southwestern of the mouth of Strymon River, are presented for the three sampling cruises (Figures 7-9). The riverine waters discharging from Strymon River (station S9) into Strymonikos Gulf seem to 


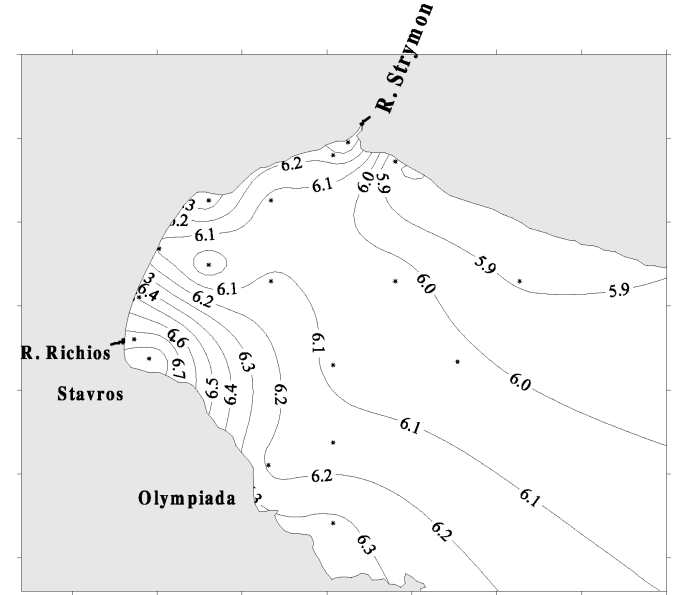

Figure 3. DO surface distribution in Strymonikos Gulf during December 1997.

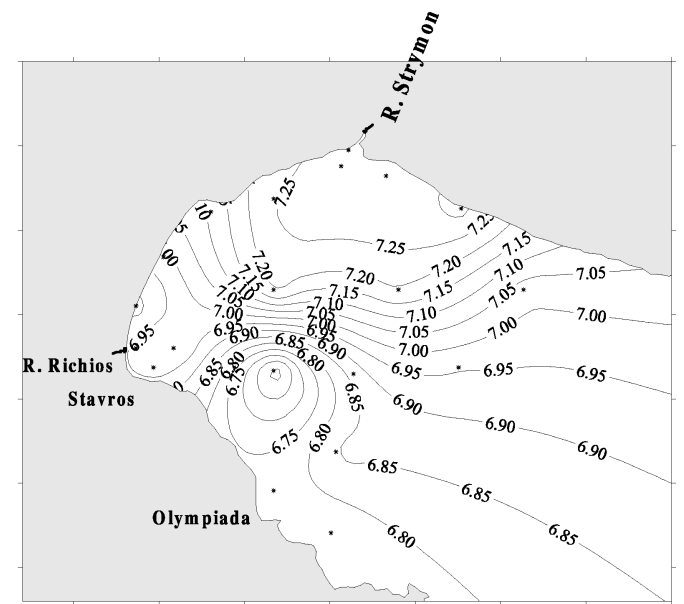

Figure 5. DO surface distribution in Strymonikos Gulf during March 1999.

move mainly towards the south-west of Strymon mouth, following an anti-clockwise movement, towards Stavros area. This pattern was followed mainly during December 1997 and March 1999, whereas during May 1998, the riverine diffusion in the coastal area was not clearly detected.

Nutrient data sets showed significant temporal (Table 1) and spatial variations in nutrient concentrations measured in Strymonikos Gulf. The principal environmental load of nutrients flowing into Strymonikos Gulf is provided by agricultural activities.

High nutrient concentrations were recorded at station S9, very close to the mouth of the river. The nutrient values measured in the coastal area of Strymonikos Gulf, close to the river mouth, (stations S9 and S10 - Figure 2) indicate a rather

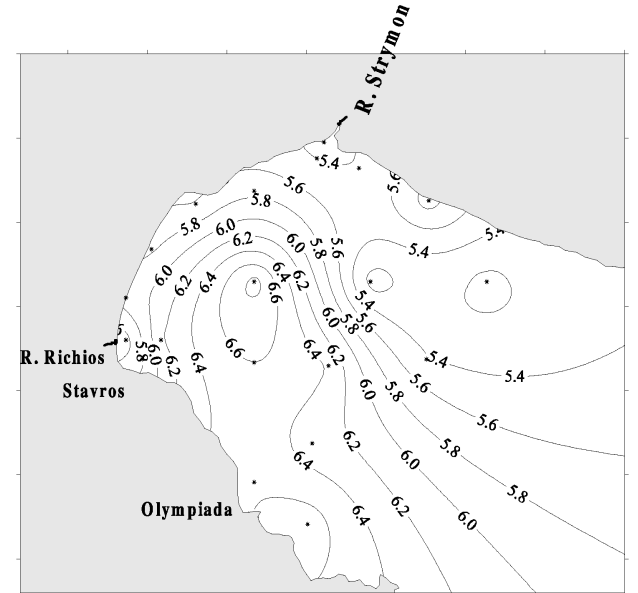

Figure 4. DO surface distribution in Strymonikos Gulf during May 1998.

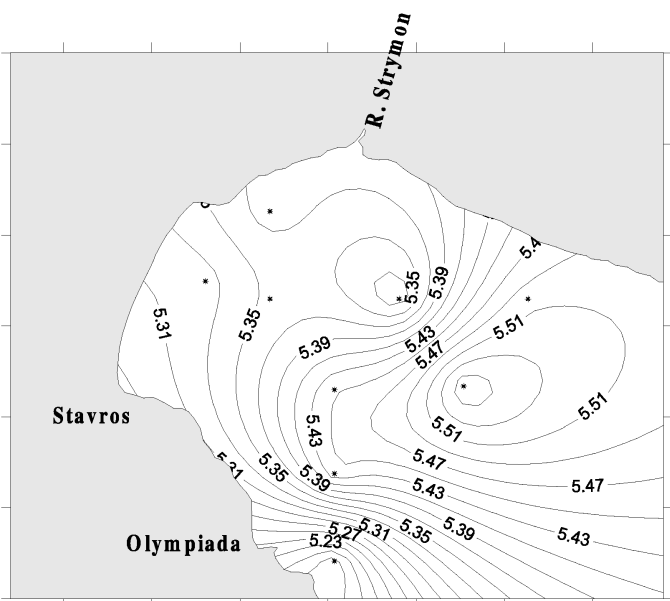

Figure 6. DO distribution at $50 \mathrm{~m}$ depth of

Strymonikos Gulf during December 1997

eutrophic environment, which is restricted near the river discharge.

\section{Silicates}

Silicate values recorded at station S9 (a representative station of the mixing zone of the riverine and estuarine water) were found to be $57 \%$ lower than those measured in the riverine waters during May 1998. A further significant decrease ( 83\%) was observed at station S10 in the marine site (Figure 2). The same pattern was also observed during March 1999.

It is noticeable that significant high values of silicates were recorded in Stavros area, during December 1997 and May 1998 (Figures 10 and 11), possibly due to the influence of Richios small River discharging in Stavros area and/or to the 


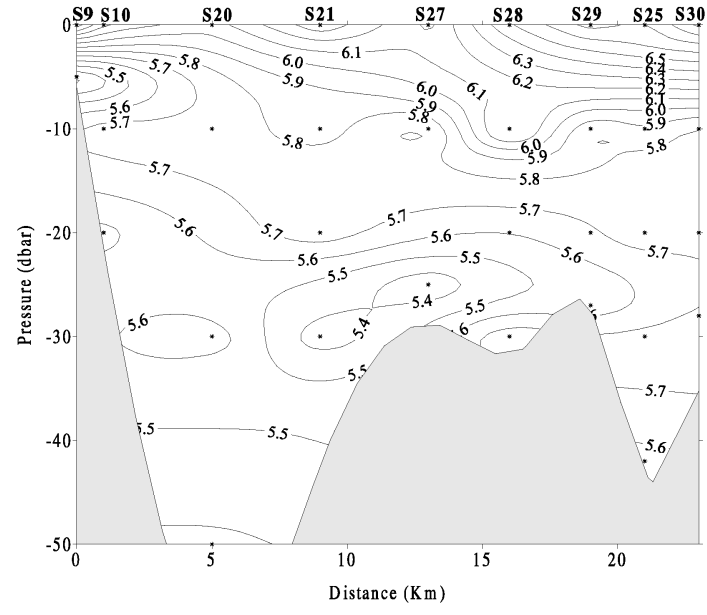

Figure 7. DO vertical distribution along a transect towards south-west of the mouth of Strymon river during December 1997.

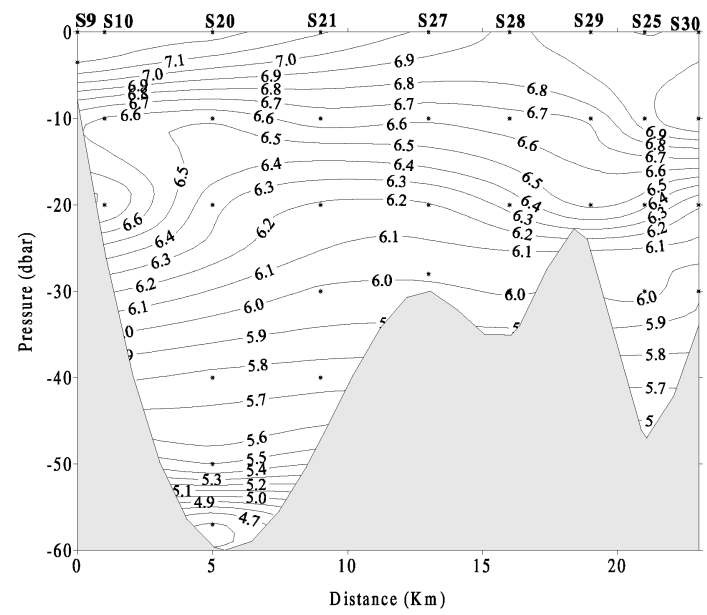

Figure 9. DO vertical distribution along a transect towards south-west of the mouth of Strymon river during March 1999.

influence of a number of streams also discharging in the area. Any other possibility is under investigation (e.g. the influence of sewage effluents, the existence of underwater springs). The enhanced silicate values in Stavros area, in December 1997, coincided with relatively low salinity values (Pavlidou, 2001b). The phenomenon declined in March 1999 (Figure 12).

The silicate levels at the surface of the stations S9 and S10, near the river plume, showed statistically no significant $(P>0.05)$ temporal variations (Table 2). The surface concentrations near the river plume were relatively high in winter and the

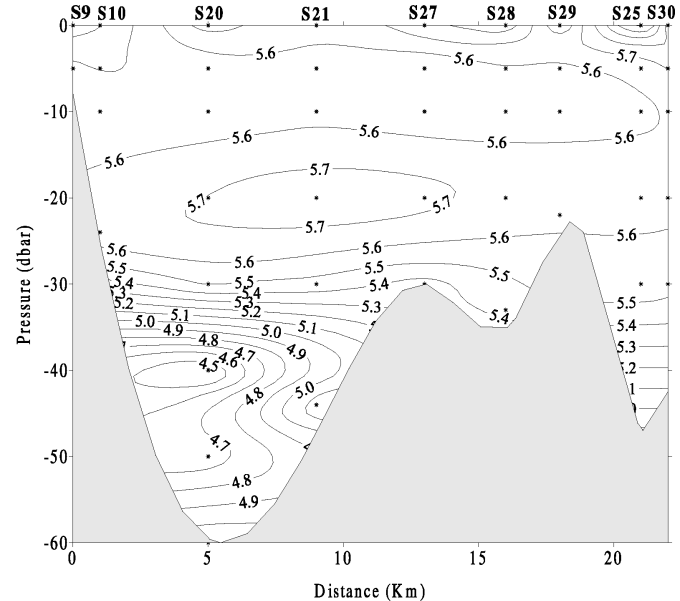

Figure 8. DO vertical distribution along a transect towards south-west of the mouth of Strymon river during May 1998.

early months of spring (i.e., December, and March), most likely due to groundwater transport and the weathering of bedrock. The decrease in late spring (May) can possibly be explained by uptake of silica by diatoms, i.e., transformation of DSi into biogenic silica (Laznic et al., 1999).

\section{Nitrates}

Nitrate behavior in Strymonikos Gulf as well as near the mouth of the river, affected by riverine waters, strongly resembles to silicate behavior. At the discharge area, a decrease $(\sim 60 \%)$ of nitrate concentration was recorded, compared to the nitrate levels found in the riverine water. This pattern resembles to the one observed for silicates, although the changes in nitrate concentrations are expected to be more complex (House and Warwick, 1998). It is difficult to discern the controlling factors influencing nitrate concentrations. The complexity of the sources, the importance of the antecedent conditions in the soil, the different pathways from the land to the river and finally to the sea, which are influenced by many factors such as agriculture in the catchment area, the antecedent conditions of the soil moisture and the nature of the fertilizers used, may be some of the factors which control the nitrate distribution. From the nutrient data collected it can be assumed that nitrogen fertilizers are mainly used at Strymon River basin. 


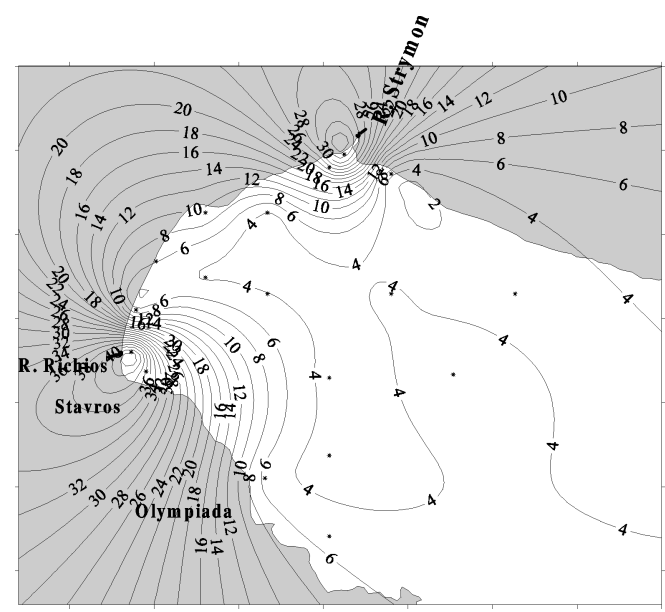

Figure 10. Surface distribution of silicates in Strymonikos Gulf during December 1997.

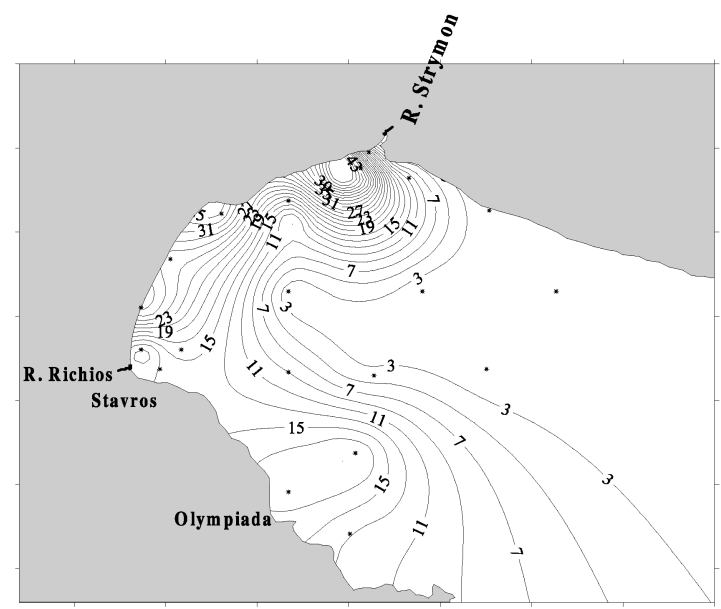

Figure 12: Surface distribution of silicates in Strymonikos Gulf during March 1999.

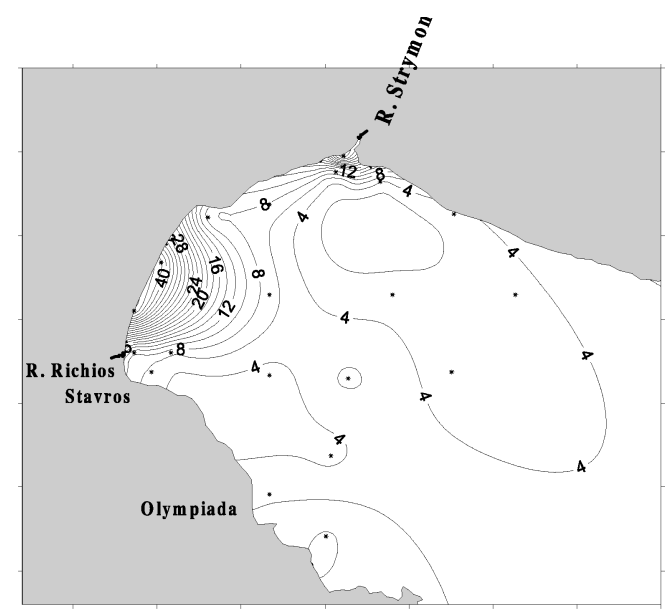

Figure 11: Surface distribution of silicates in Strymonikos Gulf during May 1998.

The surface nitrate distributions were similar to those presented for silicates (Figures 13-15). High values were recorded at Stavros area and near the river plume, like silicates.

During late spring (May) nitrate depletion was recorded near the mouth of the Strymon River, coincided to the silicate depletion (Table 2). The statistically significant $(P<0.05)$ nitrate decrease that was observed during late spring near the mouth of Strymon River, may be due to the consumption of $\mathrm{NO}_{3}-\mathrm{N}$ by phytoplankton or/and the nitrogen uptake by biota. There was not evidence of denitrification processes occurring at station S9. The increased values recorded at the surface of the stations near the river plume, during March, may be attributed to remineralisation or/and increased losses from soils, as well as to the lower biological activity (Laznic et al., 1999).

Table 2: $\quad$ Nutrient average values $\left(\mu \mathrm{mol} \mathrm{l}^{-1}\right)$ of the surface concentrations of stations S9 and S10, near the mouth of Strymon River, during the three sampling periods

\begin{tabular}{|l|c|c|c|}
\hline & December & March & May \\
\hline $\mathbf{P}^{-} \mathbf{P O}_{4}^{3-}$ & 0.52 & 0.40 & 0.87 \\
$\mathbf{S i}^{3-} \mathbf{S i O}_{4}^{2-}$ & 30.5 & 33.2 & 19.4 \\
$\mathbf{N}-\mathrm{NO}_{\mathbf{2}}^{-}$ & 0.80 & 0.48 & 1.24 \\
$\mathbf{N}-\mathrm{NO}_{\mathbf{3}}^{-}$ & 27.0 & 30.8 & 21.2 \\
$\mathbf{N}-\mathrm{NH}_{4}^{+}$ & 0.54 & 0.91 & 0.65 \\
\hline
\end{tabular}




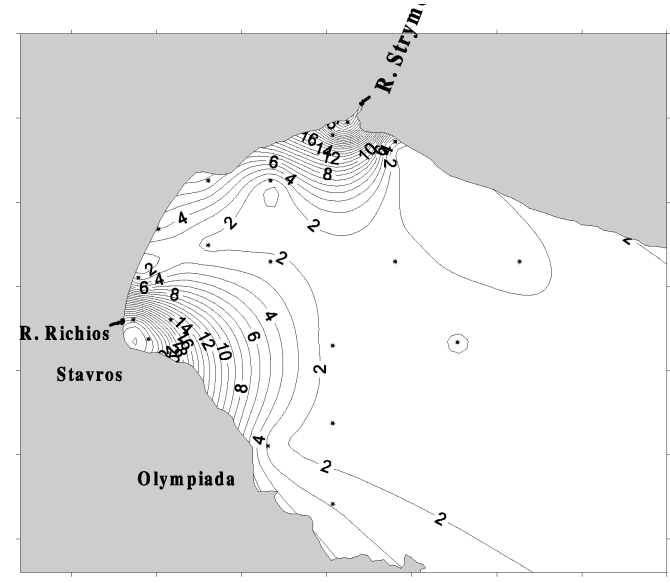

Figure 13. Surface distribution of nitrates in Strymonikos Gulf during December 1997.

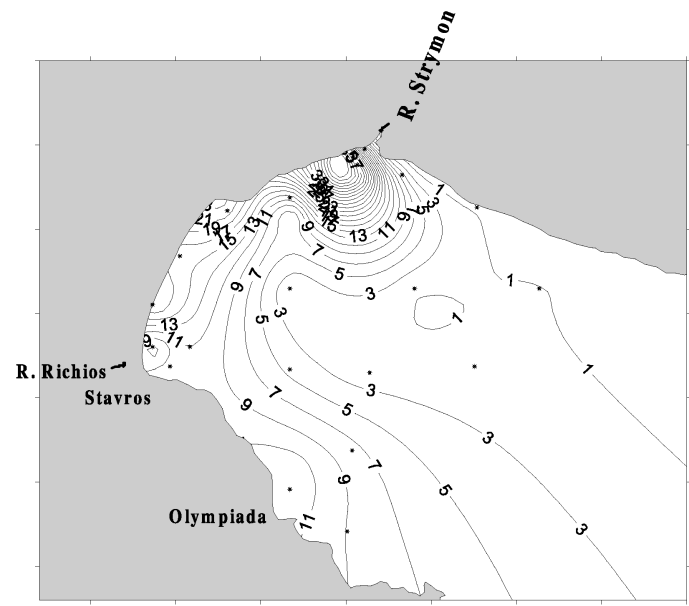

Figure 15. Surface distribution of nitrates in Strymonikos Gulf during March 1999.

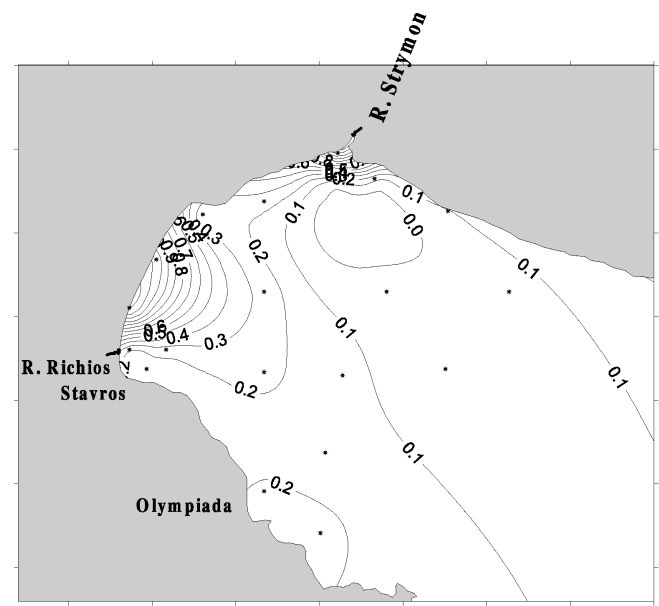

Figure 17. Surface distribution of phosphates in Strymonikos Gulf during May 1998.

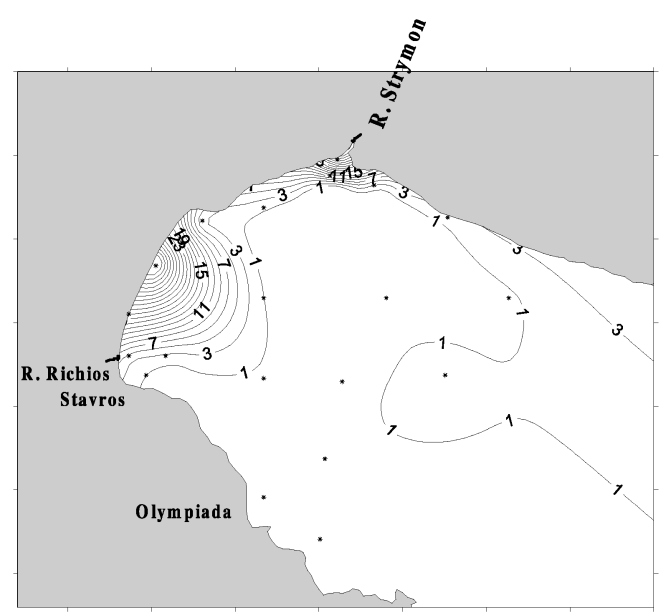

Figure 14. Surface distribution of nitrates in Strymonikos Gulf during May 1998.

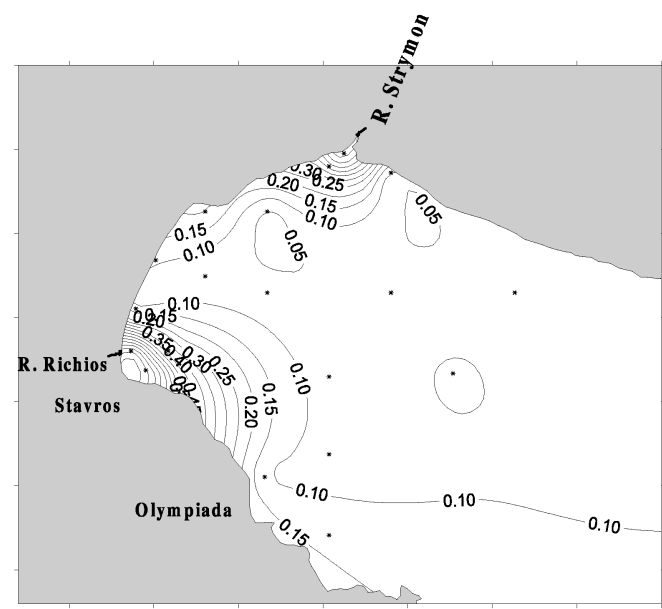

Figure 16. Surface distribution of phosphates in Strymonikos Gulf during December 1997.

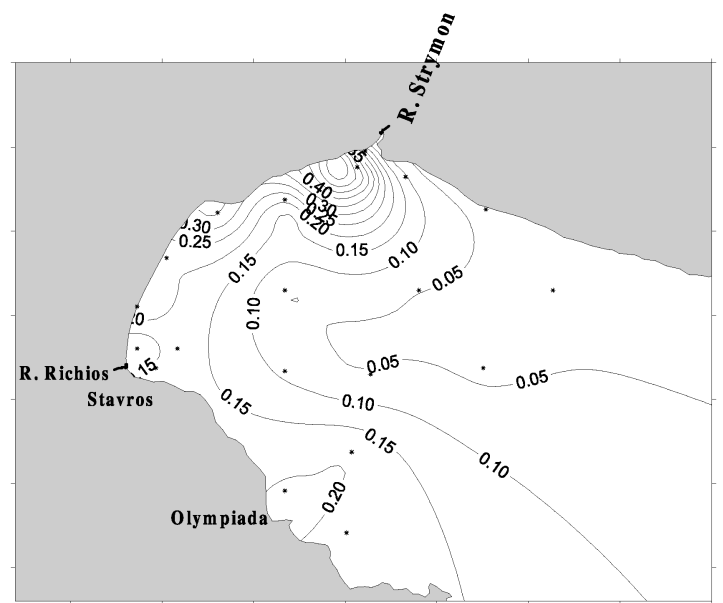

Figure 18. Surface distribution of phosphates in Strymonikos Gulf during March 1999. 


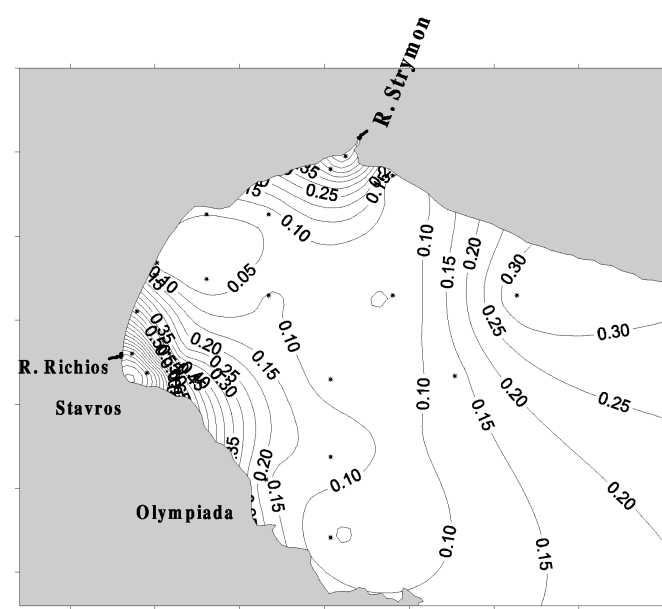

Figure 19. Surface distribution of ammonium in Strymonikos Gulf during December 1997.

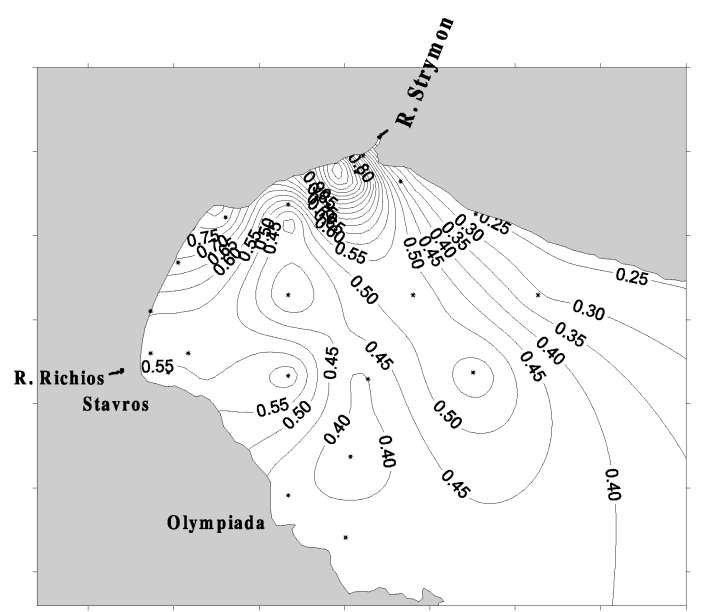

Figure 21: Surface distribution of ammonium in Strymonikos Gulf during March 1999.

\section{Phosphates}

Relatively low concentrations were measured in Strymonikos Gulf, as well as at the stations located very close to the mouth of the river. Surface distributions (Figures 16-18) showed relatively higher concentrations near the mouth of the river as well as near Stavros area during December 1997. The streams flowing into Strymonikos Gulf (between the mouth of the river and Stavros area), as well as some villages or small towns located near the coastline of Strymonikos Gulf contribute to the local enrichment of the study area in phosphates.

The spatial variation of the phosphate concentrations resembles to nitrate and silicate ones. The temporal variation of the average surface concen-

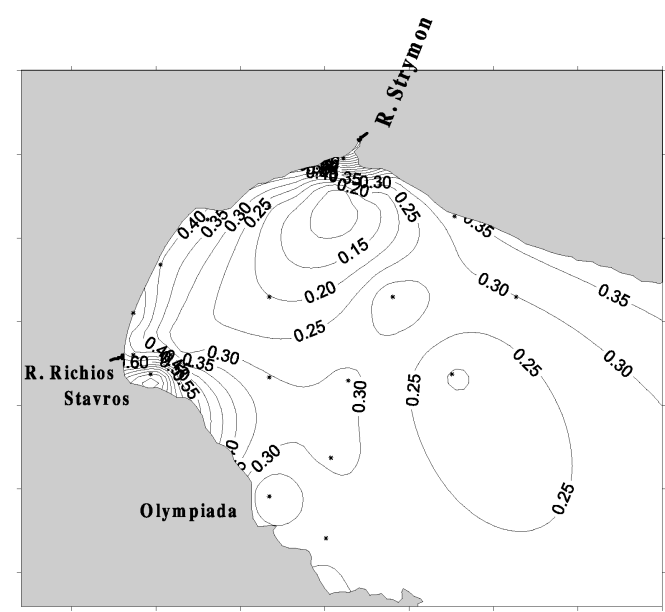

Figure 20: Surface distribution of ammonium in Strymonikos Gulf during May 1998.

trations of stations S9 and S10 appeared to be different when compared to nitrate and silicate, showing an increase during late spring, which was statistically significant $(P<0.05)$ (Table 2$)$. The increase of the phosphate content at the mouth of Strymon River during May was mainly connected with biological activities and the levels of phytoplankton, as well as with the increase of the population in the cited villages.

\section{Ammonium and nitrites}

Ammonium levels were relatively low (Table 1), indicating that there was not intense industrial and/or urban pollution (Dowling et al., 1981). However, the maximum of ammonium was measured near Stavros, which was attributed to the anthropogenic activities (i.e. sewage effluents). The low ammonium levels that were recorded at station S9, enforce the statement that Strymon River is not an industrial or urban polluted river.

Temporal variations of ammonium concentration in Strymonikos Gulf depend on the different point sources, which enrich the study area in pollutants. In the mouth of Strymon River, ammonium surface concentrations vary significantly $(P<0.05)$, showing an increase from winter period to early spring, whereas during late spring a statistically significant decrease was observed (Table 2). Relative high ammonium concentration was recorded at station $\mathrm{S}$ 9, during May, attributed probably to the small anthropogenic pollution of the river. The ammonium temporal variation resembles to the phosphate one. 


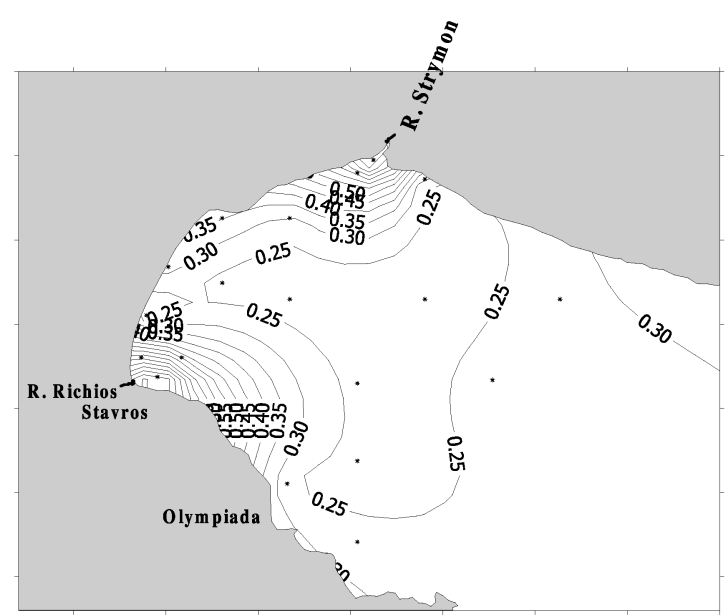

Figure 22. Surface distribution of nitrite in Strymonikos Gulf during December 1997.

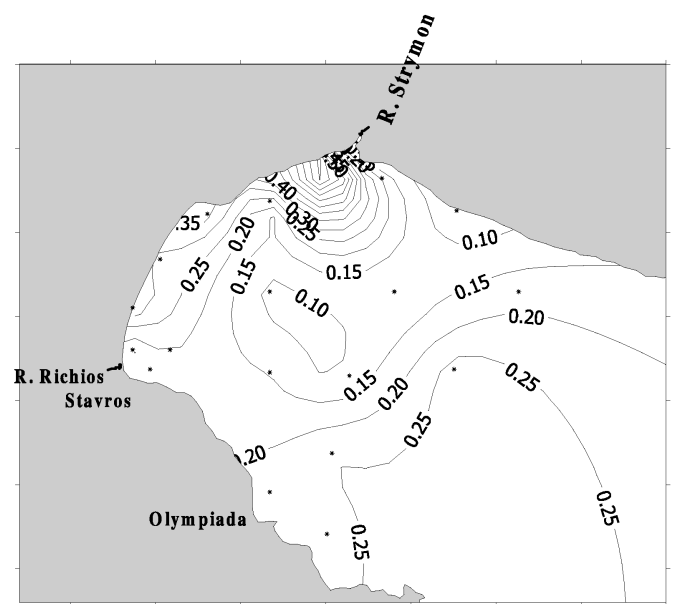

Figure 24. Surface distribution of nitrite in Strymonikos Gulf during March 1999.

Nitrites are considered an indicator of organic pollution (Scoullos, 1997). Nitrite data showed relatively high concentrations during the three sampling cruises $\left(>1 \mu \mathrm{mol} \mathrm{l}^{-1}\right)$. High nitrite levels were recorded both at station $\mathrm{S} 9$ at the mouth of Strymon River and at station S30, at Stavros area. It seems that Strymon River as well as Stavros area (Stavros town and/or Richios River) are the two main sources of organic pollutants in Strymonikos Gulf (Figures 22-24). However, since the ammonium values were low enough with insignificant changes, it can be assumed that during December a local organic pollution near Stavros as well as near the mouth of Strymon River was observed, whereas in May the pollution of the River was prominent. It is noteworthy that

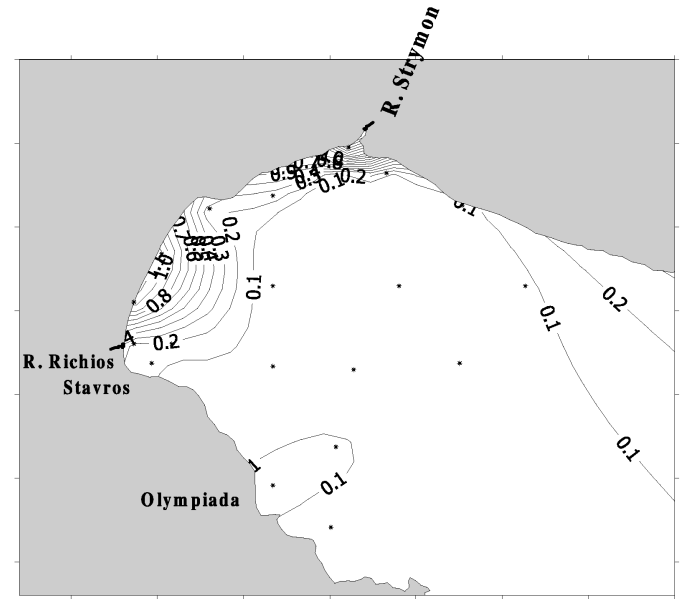

Figure 23. Surface distribution of nitrite in Strymonikos Gulf during May 1998.

any kind of pollution in the study area was very restricted and was kept at very low levels.

\section{Nutrient limitation}

The information about DIN:P ratios of soluble nutrients was used to provide an indication of the potential for nutrient limitation for either $\mathrm{N}$ or $\mathrm{P}$. Nutrient limitation may occur when a nutrient concentration falls below the level necessary for saturation of uptake. DIN showed a strong positive correlation with $\mathrm{P}(R=0.80)$ in Strymonikos Gulf.

Criteria for stoichiometric nutrient limitation have been developed based on nutrient requirements of diatoms. According to Redfield et al. (1963), the atomic Si:N:P ratio for marine diatoms is about 16:16:1, when nutrient levels are sufficient. Thereby, ratios of dissolved nutrients can be compared to the Redfield values in order to identify the limited nutrient. It seems that $50 \%$ of the data of Strymonikos Gulf follow the criterion of DIN:P > 16:1.

Justic et al., (1995), have calculated two ambient nutrient ratios for each nutrient and applied three criteria, for P-limitation, N-limitation and Si-limitation, as follows:

a) P-limitation, if Si:P>22 and DIN:P $>22$

b) N-limitation, if DIN:P $<10$ and $\mathrm{Si}: \mathrm{DIN}>1$

c) Si-limitation, if Si:P $<10$ and $\mathrm{Si}: \mathrm{DIN}<1$.

Plots of atomic DIN:P, Si:P and Si:DIN ratios in Strymonikos (including all the data of Strymonikos Gulf, $(n=280)$ during the three sampling periods studied (Figure 25), indicated stoichiometric P- 

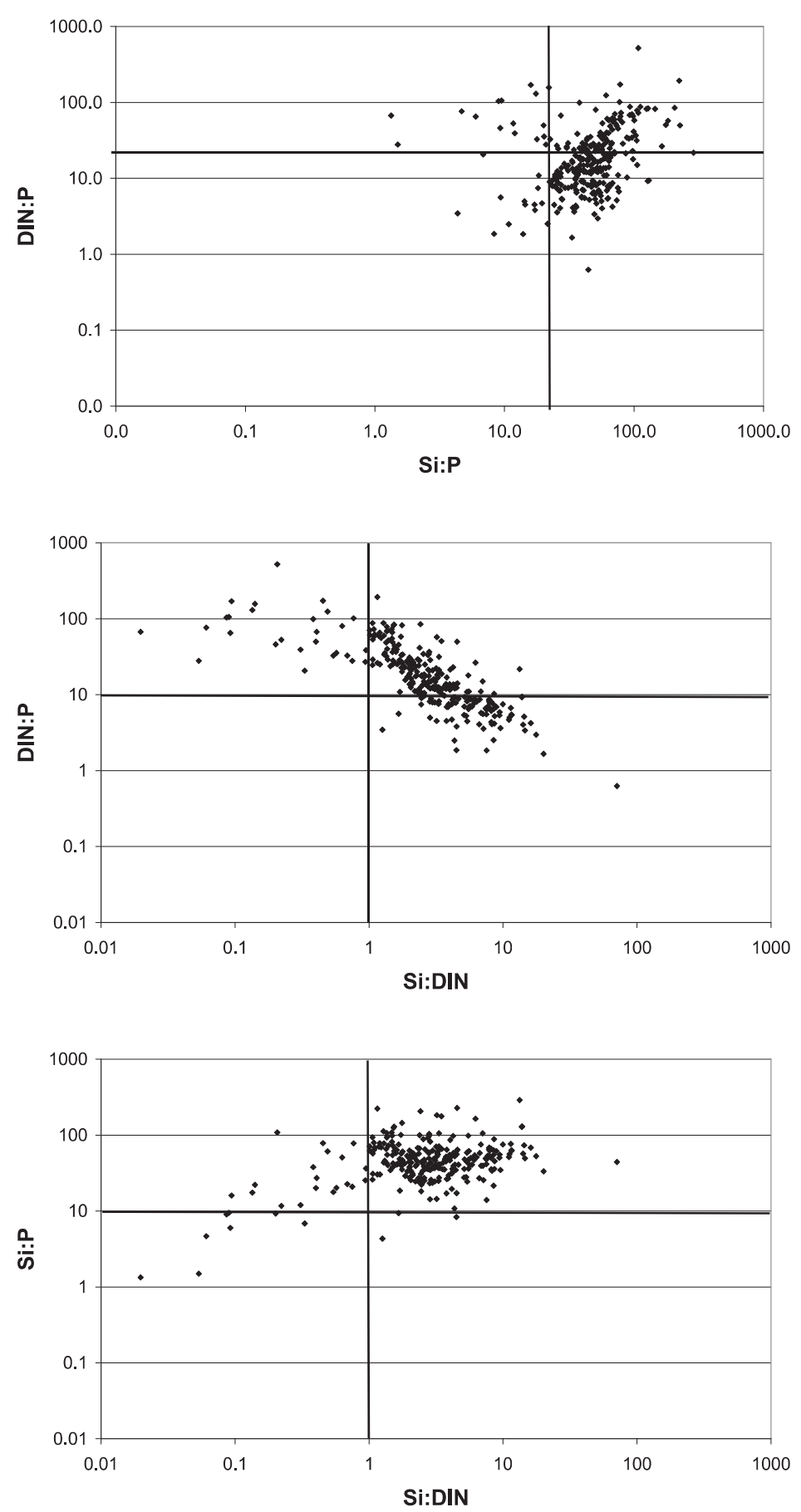

Figure 25. Scatter diagrams of atomic nutrient ratios in Strymonikos Gulf, P, dissolved inorganic P, DIN, dissolved inorganic N, Si, dissolved $\mathrm{Si}$

limitation by about $34 \%$. Furthermore, the data indicated significant probable N-limitation (31.4\%), while Si-limitation was not probable $(2.9 \%)$. It seems that the nutrient limitation is very complicated in Strymonikos Gulf.
In particular, $31 \%$ of the data showed a defined P-limitation in December, whereas $30 \%$ of the data showed N-limitation. It is noteworthy that Si-limitation was not detected. In May, the atomic DIN:P ratio indicated P-limitation in about 


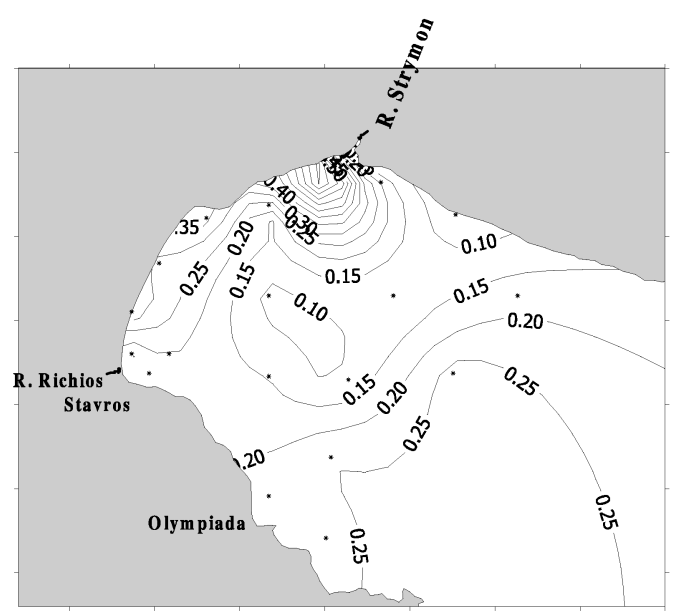

Figure 26. Surface distribution of DIN:P in

Strymonikos Gulf during December 1997.

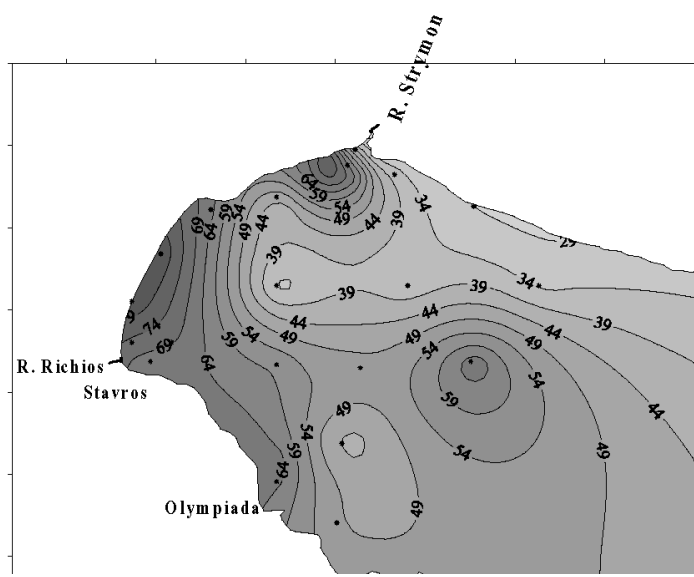

Figure 28. Surface distribution of DIN:P in

Strymonikos Gulf during March 1999.

$21 \%$ and N-limitation in about $46 \%$. Si-limitation was not detected. Finally, in March the $51 \%$ of the data showed P-limitation, whereas only the $16 \%$ showed N-limitation and $8 \%$ showed Si-limitation.

Significant changes in DIN:P ratio were observed during the hydrological cruises. During December, the stations near the mouth of Strymon River were P-limited, influenced by the riverine waters. As mixing with offshore waters progressed, the decline of N-levels increased the probability for N-limitation (Figure 26). During May (late spring) N-limitation was mainly observed (Figure 27), whereas, during March (early spring) P-limitation predominated in the study area of Strymonikos Gulf (Figure 28). DIN:P ratios varied seasonally from

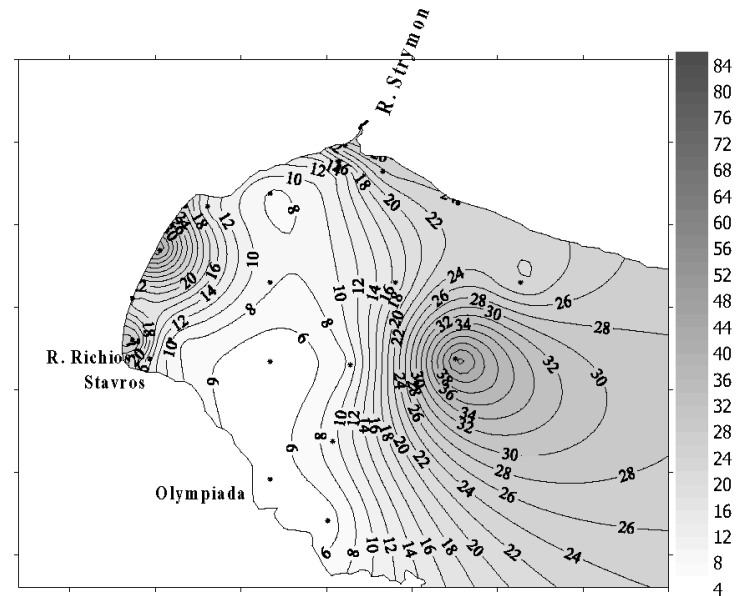

Figure 27. Surface distribution of DIN:P in Strymonikos Gulf during May 1998.

high values during winter and early spring to lower values at late spring-early summer (Figures 2628).This led to a shift from likelihood for P-limitation during winter and early spring to N-limitation in late spring-early summer. Similar variations have been observed in other estuaries as well (Lohrenz et al., 1999).

\section{Statistical analysis}

Although statistically significant temporal differences were observed for the surface data of the stations S9 and S10 near the mouth of Strymon River, it seemed that in the whole study area, when the data of all the stations and depths were compared, no statistically significant differences $(\mathrm{P}>0.05)$ between the three periods were found. The significance of difference in nutrient concentrations between the three study periods was assessed by a $t$ test. On the contrary, significant difference $(P<0.05)$ was found in the DIN:P ratio between the three periods studied. Similarly, it was found that there was a statistically significant differentiation in the frequency of P-limitation between December 1998 and March 1999.

\section{CONCLUSIONS}

Nutrient levels, which were preliminarily measured in Strymon River, found to be similar with other rather unpolluted international rivers. The influence of Strymon River on nutrient distribution in Strymonikos Gulf is restricted close to the mouth of the river, where high nutrient concentrations were recorded. Nutrient distribution showed significant spatial variations. It is note- 
worthy, that the atomic DIN:P and Si:P ratios calculated in Strymon River were significantly high. It seems that Strymon River carried dissolved inorganic $\mathrm{N}$ and $\mathrm{Si}$ in excess of dissolved inorganic $\mathrm{P}$, thus contributing to $\mathrm{P}$ deficiency in the river plume and adjacent coastal waters. DIN:P ratios varied seasonally from high values during winter and early spring to lower values at late springearly summer. This led to a shift from likelihood $\mathrm{P}$-limitation during winter and early spring to $\mathrm{N}$ limitation in late spring-early summer. Statistical analysis showed quite significant changes in nutrient limitation between the different hydrographic cruises.

\section{REFERENCES}

Bode, A. and Dortch, Q. (1996), Uptake and regeneration of inorganic nitrogen in coastal waters influenced by the Mississippi River: spatial and seasonal variations, Journal of Plankton Research, 18, 2251-2268.

Carritt, D.E. and Carpenter, J.H. (1960), Comparison and evaluation of currently employed modifications of the Winkler method for determining dissolved oxygen in seawater, J. Mar. Res., 24, 286-318.

Dortch, Q. (1999), Nutrients, irradiance, and mixing as factors regulating primary production in coastal waters impacted by the Mississippi River plume, Continental Shelf Research, 19, 113-1141.

Dowling, C., O’Conor, M., O’Grady, M.F. and Clydes, E. (1981), A baseline survey of the Caragh, an unpolluted river in SW Ireland, J. Life Sci. R. Dubl. Soc., 2, 137-145.

Friligos, N., Balopoulos, E.T. and Psyllidou-Giouranovits, R. (1997), Eutrophication and hydrography in the Amvrakikos Gulf Ionian Sea, Fresenious Envir. Bull., 6, 21-26.

House, W.A. and Warwick, M.S. (1998), Intensive measurements of nutrient dynamics in the River Swale, The Science of the Total Environment, 210/211, 111-137.

Ignadiades, L., Karydis, M. and Vounatsou, P. (1992), A possible method for evaluating oligotrophy and eutrophication based on nutrient concentration scales, Mar. Pol. Bull., 24, 238-243.

Jarvie, H.P., Whitton, B.A. and Neal, C. (1998), Nitrogen and phosphorus in east British rivers: Speciation, sources and biological significance, The Science of the Total Environment, 210/211, 79-109.

Justic, D., Rabalais, N., Turner, R. and Dortch, Q. (1995), Changes in Nutrient structure of River-dominated Coastal Waters: Stoichiometric Nutrient Balance and its Consequences, Estuarine, Coastal and Shelf Science, 40, 339-356.

Kormas, K. (1999), Nutrients, chlorophyll- $\alpha$, and suspended matter of the river Spercheios, Fresenius Envir. Bull., 8, 18-23.

Koroleff, F. (1970), Revised version of "Direct determination of ammonia in natural waters as indophenol blue". Int. Con. Explor. Sea C. M. 1969/ C:9 ICES information on techniques and methods for sea water analysis. Interlab. Rep., 3, 19-22.

Lazaridou, M., Polyzonis E. and Arvanitidis, N.D. (2001), Water Capacity and Heavy Metals Compositional Trends in Greek - Bulgarian Rivers across the Rhodope Mountains, Proceedings of INTEREG Meeting, Kavala 2001, in press.

Laznic, M., Stalnacke, P., Grimvall, A. and Wittgren, H.B. (1999), Riverine input of nutrients to the Gulf of Riga - Temporal and spatial variation, Journal of Marine Systems, 23, 11-25.

Lohrenz, S., Fahnenstiel, G., Redalje, D., Lang, G., Dagg., M. and Whitledge, T. (1999), Nutrients, irradiance, and mixing as factors regulating primary production in coastal waters impacted by the Mississippi River plume, Continental Shelf Research, 19, 1113-1141.

Meybeck, M. (1982), Carbon, nitrogen and phosphorus transport by world rivers, Am. J. Sci., 282, 401-450.

Mullin, J.B. and Riley, J.P. (1955), The colorimetric determination of silicate with special reference to sea and natural waters, Anal. Chim. Acta, 12, 162-176.

Murphy, J. and Riley, J.P. (1962), A modified single solution method for phosphate in natural waters, Anal. Chim. Acta, 12, 162-176.

Officer, C.B. and Ryther, J.H. (1980), The possible importance of silicon in marine eutrophication, Marine Ecology Progress Series, 3, 83-91.

Pavlidou, A. and Krasakopoulou, E. (2000), Dissolved Oxygen and nutrients in the water column of the inner Thermaikos Gulf. In: Monitoring of the Thermaikos Gulf ecosystem during 1997, Pagou, K. et al. (ed.), Final Report NCMR.

Pavlidou, A. and Psillidou-Giouranovits, R. (2001a), Chemical parameters. In: Monitoring of the Saronikos Gulf ecosystem affected by the Psittalia sea outfalls, Siokou-Fragou (ed.), Intermediate Report, NCMR, 34-59. 
Pavlidou, A., Papadopoulos, V. and Zervakis, V. (2001b), The influence of Strymon River on Dissolved Oxygen and Nutrient Distribution in Strymonikos Gulf, North Aegean Sea, Greece, Proceedings on $7^{\text {th }}$ International Conference of Environmental Science and Technology, Syros 2001, C, 403-409.

Pyrovetsi, M. and Papastergiadou, E. (1992), Biological conservation implications of water-level fluctuations in a wetland of international importance: lake Kerkini, Macedonia Greece, Environmental Conservation, 19, 235-244.

Redfield, A.C., Ketchum, B.H. and Richards, F.A. (1963), The influence of organisms on the composition of seawater, In: The Sea (ed. Hill, M.N), 2, 26-77.

Riley, J.P. (1975), Determination of dissolved gases. In: Riley, J.P. (ed.) Chemical Oceanography, $2^{\text {nd }}$ edition, $\mathbf{3}$, 253.

Scoullos, M. (1997), Sea pollution. In: Chemical Oceanography B, $3^{\text {rd }}$ edition. Athens University, 194 (in Greek).

Scoulikidis, N. (1997), Interegional rivers entering Greece-Composition, transport of matter, intra-annual and inter-annual variations, Proceedings on $5^{\text {th }}$ National Conference of Oceanography and Fishing, 2, 297-300.

Strickland, J.D.H. and Parsons, T.R. (1968), A practical handbook of sea water analysis, Bull. Fish. Res. Bd. Canada, 167, 310.

Tryfon, E., Moustaka-Gouni, M. and Nikolaidis, G. (1996), Phytoplankton and Nutrients in the river Strymon, Greece, Internationale Revue der Gesamten Hydrobiologie, 81, 281-192.

Veleva, R. (2000), The water resources in the section of corridor $\mathrm{n} 8$ from the Western border to the city of Sofia, Balkan Review, 2, 32-26.

Zhang, J., Yu, Z.G., Wang, J.L., Ren, H.T., Chen, H., Xion, L.X. and Zu., W.Y. (1999), The Subtropical Zhujiang (Pearl River) Estuary: Nutrient, Trace Species and their relationship to photosynthesis, Estuarine, Coastal and Shelf Science, 49, 385-400. 